\title{
Childhood BMI in relation to microbiota in infancy and lifetime antibiotic use
}

\author{
K. Korpela ${ }^{1^{*}}$ (D, M. A. C. Zijlmans ${ }^{2}$, M. Kuitunen ${ }^{3}$, K. Kukkonen ${ }^{4}$, E. Savilahti ${ }^{3}$, A. Salonen ${ }^{1}$, C. de Weerth ${ }^{2}$ \\ and W. M. de Vos ${ }^{1,5}$
}

\begin{abstract}
Background: Children with high body mass index (BMI) at preschool age are at risk of developing obesity. Early identification of factors that increase the risk of excessive weight gain could help direct preventive actions. The intestinal microbiota and antibiotic use have been identified as potential modulators of early metabolic programming and weight development. To test if the early microbiota composition is associated with later BMl, and if antibiotic use modifies this association, we analysed the faecal microbiota composition at 3 months and the BMI at 5-6 years in two cohorts of healthy children born vaginally at term in the Netherlands $(N=87)$ and Finland $(N=75)$. We obtained lifetime antibiotic use records and measured weight and height of all children.

Results: The relative abundance of streptococci was positively and the relative abundance of bifidobacteria negatively associated with the BMI outcome. The association was especially strong among children with a history of antibiotic use. Bacteroides relative abundance was associated with BMI only in the children with minimal lifetime antibiotic exposure.

Conclusions: The intestinal microbiota of infants are predictive of later BMI and may serve as an early indicator of obesity risk. Bifidobacteria and streptococci, which are indicators of microbiota maturation in infants, are likely candidates for metabolic programming of infants, and their influence on BMI appears to depend on later antibiotic use.
\end{abstract}

Keywords: Early-life microbiota, Childhood overweight, Bifidobacteria, Metabolic programming, Microarray

\section{Background}

Overweight in childhood is an increasing global health problem with complex aetiology [1] and long-term consequences on the individual's health, as it predisposes to cardiovascular risk factors, such as diabetes, hyperlipidemia, and increased blood pressure [1], and represents an important risk factor for adulthood obesity [2]. Preand perinatal maternal and environmental factors are being recognized as important contributors to the longterm metabolic programming and weight development of infants, and multiple lines of evidence indicate that childhood overweight may be strongly dependent on early-life influences [3]. The intestinal microbiota, acquired initially during birth from the mother and

\footnotetext{
* Correspondence: katri.korpela@helsinki.fi

${ }^{1}$ Immunobiology Research Program, Department of Bacteriology and Immunology, University of Helsinki, Haartmaninkatu 3, PO box 2100014 Helsinki, Finland

Full list of author information is available at the end of the article
}

nurtured by breast milk, are emerging as an important modulator of early metabolic programming.

Mouse studies indicate a causal role for the intestinal microbiota regulating the development of growth, energy metabolism, fat accumulation, and susceptibility to dietinduced adiposity [4-6], a phenomenon termed microbiota-induced obesity [7]. Intestinal microbiota composition in infancy [8-12] and antibiotic use in early childhood [13-17] have been repeatedly associated with subsequent weight development in children. Mouse studies have established that early-life microbiota disruption by antibiotics causes increased growth and adiposity $[6,18,19]$. In addition to antibiotics, other microbiotadisrupting factors, such as birth by Caesarean section and short duration of breastfeeding, convey an increased risk of overweight, which is likely mediated by the early intestinal microbiota development [20, 21].

In mice, antibiotic-induced weight gain involves similar hormonal changes as diet-induced weight gain: increased levels of leptin and decreased levels of ghrelin 
and peptide YY [6]. The common factor between an obesogenic diet and antibiotic use is that they both strongly alter the intestinal microbiota, which have the capacity to regulate the host's energy homeostasis via, e.g., FXR and TGR5 signalling by bile acids [22, 23], TLR4 signalling by lipopolysaccharide (LPS) [24, 25], Angptl4/Fiaf signalling [4, 26], and gut hormone and adipose tissue regulation by short-chain fatty acid (SCFA) production [27]. It is thus becoming increasingly evident that the early-life microbiota are involved in long-lasting metabolic programming.

We have previously discovered that the early-life use of macrolide antibiotics, which strongly modifies the microbiota, is a prerequisite for later antibioticassociated increase in BMI in healthy Finnish children [28]. We have also reported recently that long duration of breastfeeding is negatively associated with BMI at preschool age but only among children who did not receive antibiotics before weaning, i.e., whose microbiota were intact [29], suggesting that the microbiota mediate the beneficial metabolic effects of breastfeeding. We therefore hypothesised that early microbiota composition may be associated with BMI in later childhood and that antibiotic use may modify this effect. In children with low lifetime antibiotic use, the early microbiota composition may be associated with the child's susceptibility to diet-induced overweight, potentially involving leptin sensitivity or adipocyte programming [3]. In children with frequent lifetime antibiotic use, BMI is likely to be influenced not only by diet but also by the antibiotics; the early-life microbiome may thus affect the child's susceptibility to both diet-induced and antibioticassociated weight gain.

To test these hypotheses, we monitored a total of 162 children in the Netherlands and Finland, from birth to 5-6 years of age and analysed their total faecal microbiota at the age of 3 months using a cultureindependent phylogenetic microarray. A consistent set of intestinal bacteria at 3 months of age was found to predict the BMI at 5-6 years, depending on the lifetime antibiotic use. While country-specific microbiota composition was noticeable, the BMI-associated signatures were evident independent of the geographic location.

\section{Methods}

\section{Participants}

The data consist of Dutch $(N=87)$ and Finnish $(N=75)$ children comprising 162 children in total (Table 1). These were selected from large longitudinal cohorts, the Bibo cohort $(N=193)$ in the Netherlands and the Flora cohort $(N=1223)$ in Finland, which have been reported previously [30,31]. The selection criteria of the original studies included birth at term and no serious pregnancy or birth complications. For the current study, we
Table 1 Characteristics of the cohorts (mean \pm standard deviation)

\begin{tabular}{lll}
\hline & Finnish & Dutch \\
\hline$N$ & 75 & 87 \\
Birth weight $(\mathrm{kg})$ & $3.50 \pm 0.44$ & $3.64 \pm 0.46$ \\
Growth first 6 months $(\mathrm{kg}) ; N$ & $4.36 \pm 075 ; 55$ & $4.14 \pm 0.69 ; 56$ \\
Duration of breastfeeding (weeks) & $31.24 \pm 17.19$ & $14.18 \pm 11.10$ \\
Total number of antibiotic courses & $5.52 \pm 4.82$ & $2.67 \pm 2.93$ \\
BMl & $15.72 \pm 1.54$ & $15.75 \pm 1.47$ \\
\hline
\end{tabular}

selected vaginally born cases with appropriately stored faecal sample collected at 3 months and information on lifetime antibiotic use and BMI at 5-6 years. The children were measured for weight and height at the age of 5 (Flora) or 6 (Bibo) years.

In the Flora study, pregnant mothers, whose infants had increased risk for allergy (at least one parent had a diagnosed allergic disease), were recruited at antenatal clinics and through advertisements in the Helsinki (Finland) suburban area. The Flora study was a probiotic intervention study, and here, we only included infants from the control group. The study was approved by the ethical committee of the Helsinki region hospital district. The Bibo study is a longitudinal study in which mothers and their children were followed from the third trimester of pregnancy on. Pregnant women were recruited through midwife practices in Nijmegen and surrounding areas (the Netherlands).

The median birth weight was $3.4 \mathrm{~kg}$ (range $2.3-4.7 \mathrm{~kg}$ ) among the Finnish infants and $3.6 \mathrm{~kg}$ (range $2.7-4.7 \mathrm{~kg}$ ) among the Dutch infants. In the Finnish cohort, 39 infants were first-born, and in the Dutch cohort, 23 infants were first-born. At the age of 3 months, 12 Finnish infants and 42 Dutch infants were no longer breastfed. The sub-cohorts analysed here did not differ from the total Flora and Bibo cohorts in terms of birth weight, BMI, or duration of breastfeeding. In the total Flora cohort, the mean \pm sd birth weight was $3.59 \pm 0.49 \mathrm{~kg}$, duration of breastfeeding was $8.42 \pm 5.23$ months, and BMI at 5 years was $15.86 \pm 1.38$. In the total Bibo cohort, the mean \pm sd birth weight was $3.61 \pm 0.47 \mathrm{~kg}$, duration of breastfeeding was $4.19 \pm 2.78$ months, and BMI at 6 years was $15.64 \pm 1.35$.

\section{Procedure}

A faecal sample was collected from all infants at the age of 3 months, by parents at home, as previously detailed [30, 31]. In addition, information on weight development from birth to 6 months of age was available for a subset of infants in both cohorts (Table 1). Growth during the first 6 months was calculated as change in weight from birth to age 6 months. BMI at 5-6 years was calculated based on the weight and height measured by a paediatrician or a researcher. 
Lifetime antibiotic use information was available for both cohorts. For the Dutch cohort, data on antibiotic prescriptions were obtained from clinical records from the child's GP. For the Finnish children, the parents provided information on the number of antibiotic courses the child had received every 3-6 months during the first year, thereafter yearly in questionnaires. The overwhelming majority of the antibiotic courses were given to the children after the collection of the faecal samples; only eight infants received antibiotics before the age of 3 months (Fig. 1). The type of antibiotics used was not available for all infants, and therefore, only the total number of courses was used in the analysis. The level of antibiotic use was higher in the Finnish cohort: the median number of courses was 5 in the Finnish cohort and 2 in the Dutch cohort, corresponding to population-level data from both countries [32].

\section{Microbiota analysis}

The faecal samples of both cohorts were processed and analysed using a pipeline that has been used in many infant and child microbiota studies [31,33]. This included DNA extraction using the repeated bead beating method [34] and analysis of the microbiota composition using the HITChip phylogenetic microarray, which contains oligonucleotide probes for hypervariables regions on the $16 \mathrm{~S}$ rRNA gene [35]. All samples were analysed on two independent microarray experiments, and the data only passed the quality control if the inter-experiment Pearson correlation was $>0.97$. The signal intensities were normalized using the fRPA method [36] and summarised at different levels of phylogenetic resolution: species, genus, and phylum, except for the Firmicutes, which was further divided to Clostridium clusters and Bacilli. Relative normalized signal intensities were calculated for all samples and all three levels. For the

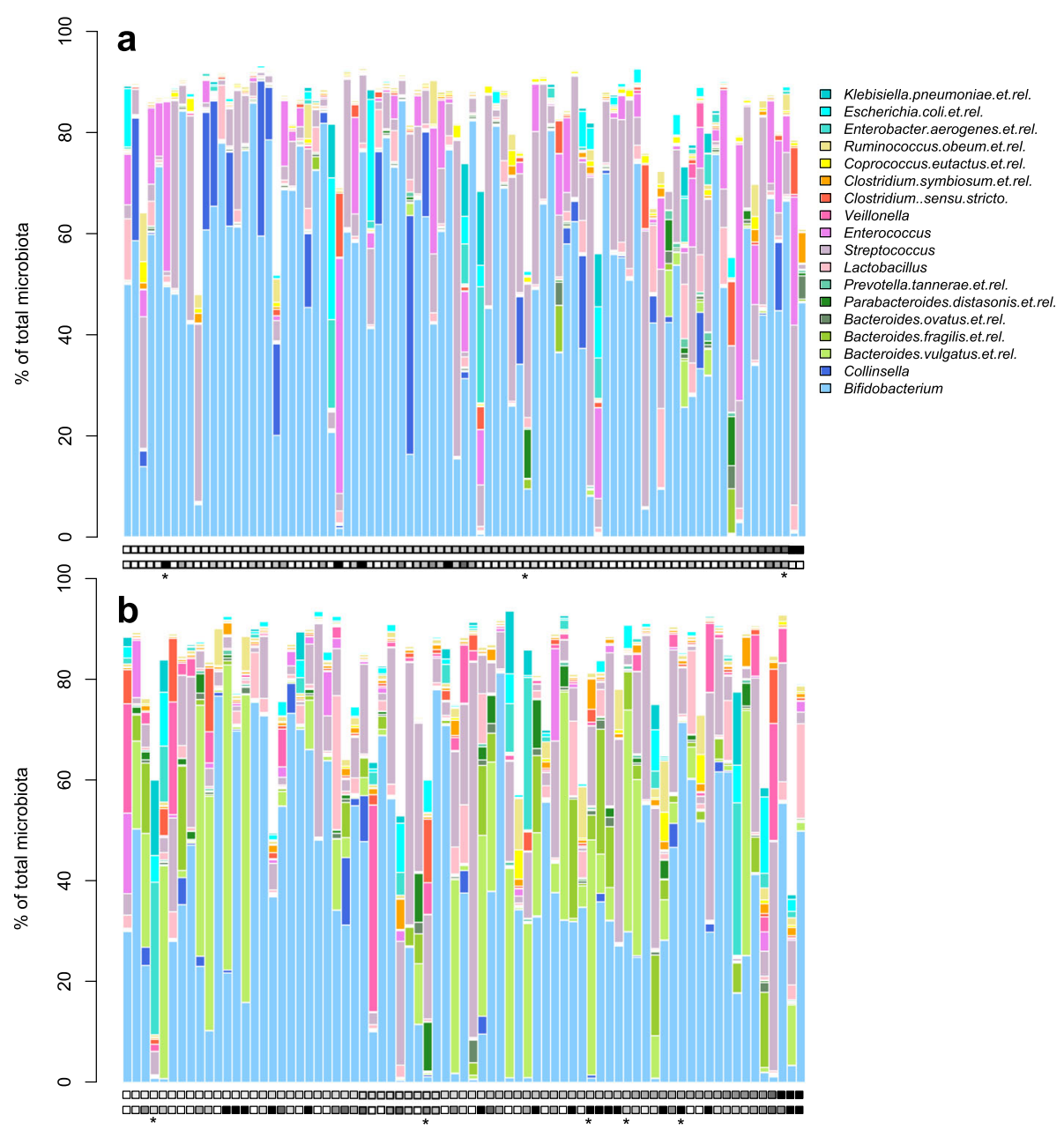

Fig. 1 Microbiota composition of 3-month-old infants in the Dutch (a) and Finnish (b) cohorts. The 16 most abundant genus-level taxa are shown. Colour codes are from top down on each column. Each column represents an individual child, and the squares below the columns show the BMl of the child at 5-6 years ( hite $=13$, black $=21$ ) and lifetime antibiotic use ( white $=0$ courses, black $=8$ or more courses). Asterisks indicate infants who had received a course of antibiotics before sample collection 
analyses, only bacterial groups with $>30 \%$ prevalence at a minimum of $0.01 \%$ relative abundance were included (Additional file 1).

\section{Statistical analysis}

Differences between the countries in bacterial relative abundances were tested using generalised linear models with negative binomial distribution. Associations between bacterial taxa to BMI and early growth were tested using correlations. To adjust for the effects of country, birth weight, breastfeeding duration, and antibiotic use on BMI, we calculated the deviance from the expected BMI, based on a linear model with the aforementioned variables. We then tested for a correlation between the BMI deviance and the log-transformed relative abundances of the bacterial taxa. The models were run using the whole data set and separately for each cohort to ascertain consistency in the associations. In addition, the models were run separately for children with minimal antibiotic exposure (0-1 lifetime courses), and those with several antibiotic courses, to see if the associations were present regardless of antibiotic exposure. Only associations that were significant in the total cohort $(p<0.05)$ and nearly significant $(p<0.15)$ in both countries separately were considered robust. All statistical analyses were conducted in R [37] using the package vegan [38]. $\mathrm{R}$ script for the analysis is available in Additional file 2.

\section{Results}

\section{Country differences}

A total of 162 intestinal microbiota profiles from 3month-old infants in the Netherlands and Finland were analysed in duplicate using an established phylogenetic microarray (Fig. 1). In the analysis, a total of 115 bacterial taxa (58 genus-like groups, 14 Clostridium cluster/ phylum groups, and 43 species-like groups) passed the abundance and prevalence filter and were included.

Although the faecal samples were processed and analysed in the same pipeline and platform, the microbiota compositions differed clearly between the countries (Fig. 1, see Additional file 3). Out of the 115 taxa, the relative abundance of 87 (76\%) differed significantly between the countries. Country explained $13 \%$ of the interindividual differences in microbiota composition $(p=$ 0.001). The most pronounced difference was the relative abundance of the genus Bacteroides, which was at a low level in the Dutch infants, but very abundant in some, but not all, Finnish infants (Fig. $1, p<0.00001$ ). Veillonella showed a similar pattern (Fig. 1, $p<0.00001$ ). Bacteria related to Enterococcus formed a major component of the microbiota in many Dutch infants, but represented a minority in the Finnish infants (Fig. 1, $p<$ 0.00001). Bifidobacterium and Streptococcus were the dominant taxa in the intestinal microbiota of both cohorts with no significant cohort difference in relative abundance ( $p=0.09$ and $p=0.44$, respectively).

\section{Association between early-life microbiota composition and BMI at the age of 5-6 years}

BMI distributions did not markedly differ between the cohorts (see Additional file 4), and most children were normal weight (BMI 14-17, according to the CDC growth charts). In both cohorts, there were also overweight children (14 Dutch and 14 Finnish children with BMI >17) and underweight children (10 Dutch and 7 Finnish children with BMI <14).

The background variables country, birth weight, breastfeeding duration, and total lifetime antibiotic use explained $11 \%$ of the BMI variation. The only significant contributor to BMI was birth weight $(p=0.0005)$. Antibiotic use had a nearly significant positive association with BMI $(p=0.06)$.

The relative abundance of the phylum Actinobacteria was negatively and the relative abundance of the phylum Firmicutes was positively associated with BMI (Table 2). Among Actinobacteria, the most abundant genus Bifidobacterium-particularly the species $B$. infantis, $B$. pseudocatenulatum, $B$. longum, and $B$. thermophilum-was negatively associated with BMI (Table 2, Fig. 2a). Among Firmicutes, the class Bacilli, and particularly streptococci, were positively associated with BMI (Table 2, Fig. 2b). However, these associations varied by antibiotic exposure and were not present in the children with minimal antibiotic exposure (Table 2, Fig. 3). Among the children with minimal antibiotic exposure, there was a strong positive association between BMI and Bacteroidetes, particularly species related to Bacteroides ovatus, Bacteroides vulgatus, and Prevotella tannerae (Table 2, Fig. 3). Conversely, the phylum Firmicutes showed a significant positive association with BMI only among the children with a history of several antibiotic courses (Table 2, Fig. 3).

\section{Microbiota composition and early growth}

The associations between BMI and microbiota composition were largely reflected in the associations between microbiota and early growth (Fig. 3). Early growth was positively associated with the relative abundance of Firmicutes at 3 months (correlation = 0.21 [0.03-0.39], $p=0.02)$, particularly Clostridia $(0.20$ [0.01-0.37], $p=0.04)$, and species related to Streptococcus bovis (0.2 [0.02-0.39], $p=0.03)$.

\section{Discussion}

We compared the early-life faecal microbiota compositions in two cohorts of healthy infants and identified bacterial taxa whose relative abundances were 
Table 2 Correlations (95\% confidence interval) between bacterial taxa and BMI, adjusted for birth weight and duration of breastfeeding, in the total cohort $(N=162)$, in children with minimal antibiotic exposure (0-1 lifetime courses, $N=50)$, and children with several antibiotic courses $(N=112)$

\begin{tabular}{|c|c|c|c|c|c|c|}
\hline Taxon & All & $p$ & Minimal $A B$ & $p$ & Several $A B$ & $p$ \\
\hline Actinobacteria & $-0.21(-0.36$ to -0.06$)$ & 0.01 & $-0.05(-0.33$ to 0.25$)$ & 0.76 & $-0.28(-0.45$ to -0.09$)$ & $<0.01$ \\
\hline Bifidobacterium & $-0.21(-0.36$ to -0.05$)$ & 0.01 & $-0.05(-0.33$ to 0.25$)$ & 0.76 & $-0.27(-0.44$ to -0.09$)$ & $<0.01$ \\
\hline Bifidobacterium infantis & $-0.19(-0.34$ to -0.04$)$ & 0.02 & $-0.05(-0.33$ to 0.25$)$ & 0.76 & $-0.23(-0.4$ to -0.04$)$ & 0.02 \\
\hline Bifidobacterium longum & $-0.2(-0.34$ to -0.04$)$ & 0.02 & $-0.04(-0.33$ to 0.25$)$ & 0.77 & $-0.24(-0.41$ to -0.05$)$ & 0.01 \\
\hline Bifidobacterium pseudocatenulatum & $-0.16(-0.31$ to 0$)$ & 0.05 & $0.04(-0.25$ to 0.33$)$ & 0.78 & $-0.25(-0.42$ to -0.06$)$ & 0.01 \\
\hline Bifidobacterium thermophilum & $-0.16(-0.31$ to 0$)$ & 0.05 & $0.06(-0.23$ to 0.34$)$ & 0.69 & $-0.24(-0.41$ to -0.05$)$ & 0.01 \\
\hline Bacteroidetes & $0.05(-0.11$ to 0.2$)$ & 0.57 & 0.3 (0.01 to 0.55$)$ & 0.04 & $-0.02(-0.21$ to 0.18$)$ & 0.88 \\
\hline Bacteroides & $0.06(-0.1$ to 0.21$)$ & 0.5 & 0.31 (0.02 to 0.55$)$ & 0.04 & $0(-0.19$ to 0.19$)$ & 0.99 \\
\hline Bacteroides ovatus et rel & $0.05(-0.11$ to 0.2$)$ & 0.57 & 0.36 (0.07 to 0.59$)$ & 0.02 & $-0.04(-0.23$ to 0.15$)$ & 0.69 \\
\hline Bacteroides vulgatus et rel & $0.07(-0.09$ to 0.22$)$ & 0.41 & 0.34 (0.06 to 0.57$)$ & 0.02 & $-0.01(-0.2$ to 0.18$)$ & 0.92 \\
\hline Prevotella tannerae et rel & $0.13(-0.03$ to 0.28$)$ & 0.11 & 0.49 (0.23 to 0.68$)$ & 0 & $-0.01(-0.2$ to 0.18$)$ & 0.91 \\
\hline Firmicutes & 0.23 (0.08 to 0.38 ) & $<0.01$ & $-0.05(-0.33$ to 0.25$)$ & 0.76 & $0.34(0.16$ to 0.5$)$ & $<0.01$ \\
\hline Clostridia & $0.08(-0.09$ to 0.23$)$ & 0.36 & $-0.26(-0.51$ to 0.03$)$ & 0.08 & 0.21 (0.02 to 0.39$)$ & 0.03 \\
\hline Lachnospira pectinoschiza et rel & $0.15(-0.01$ to 0.31$)$ & 0.06 & $0.02(-0.27$ to 0.31$)$ & 0.9 & $0.23(0.04$ to 0.4$)$ & 0.02 \\
\hline Bacilli & 0.25 (0.09 to 0.39) & $<0.01$ & 0.21 (-0.09 to 0.47$)$ & 0.17 & 0.25 (0.06 to 0.42$)$ & 0.01 \\
\hline Streptococcus & $0.26(0.11$ to 0.4$)$ & $<0.01$ & $0.07(-0.22$ to 0.35$)$ & 0.64 & 0.31 (0.13 to 0.48$)$ & $<0.01$ \\
\hline Streptococcus bovis et rel & 0.24 (0.08 to 0.38$)$ & $<0.01$ & $-0.02(-0.31$ to 0.28$)$ & 0.92 & $0.29(0.1$ to 0.46$)$ & $<0.01$ \\
\hline Streptococcus intermedius et rel & 0.22 (0.06 to 0.36$)$ & 0.01 & $0.23(-0.06$ to 0.49$)$ & 0.12 & 0.21 (0.02 to 0.38$)$ & 0.03 \\
\hline Streptococcus mitis & 0.22 (0.06 to 0.37) & 0.01 & $0.24(-0.05$ to 0.5$)$ & 0.1 & 0.21 (0.02 to 0.38$)$ & 0.03 \\
\hline Streptococcus mitis et rel & $0.26(0.11$ to 0.41$)$ & $<0.01$ & $0.1(-0.2$ to 0.38$)$ & 0.52 & 0.32 (0.13 to 0.48$)$ & $<0.01$ \\
\hline Streptococcus mutans & 0.18 (0.02 to 0.33$)$ & 0.03 & 0.18 (-0.11 to 0.45$)$ & 0.22 & $0.18(-0.01$ to 0.36$)$ & 0.06 \\
\hline Streptococcus parasanguinis & 0.21 (0.05 to 0.36) & 0.01 & 0.21 (-0.09 to 0.47$)$ & 0.17 & 0.21 (0.02 to 0.39$)$ & 0.03 \\
\hline Streptococcus pneumoniae & 0.19 (0.03 to 0.34$)$ & 0.02 & $0.07(-0.22$ to 0.36$)$ & 0.63 & 0.22 (0.03 to 0.39$)$ & 0.02 \\
\hline Streptococcus salivarius & 0.24 (0.08 to 0.39$)$ & $<0.01$ & $0.07(-0.23$ to 0.35$)$ & 0.65 & $0.28(0.1$ to 0.45$)$ & $<0.01$ \\
\hline Streptococcus sanguis & 0.28 (0.12 to 0.42$)$ & $<0.01$ & $0.03(-0.26$ to 0.32$)$ & 0.82 & $0.34(0.16$ to 0.5$)$ & $<0.01$ \\
\hline
\end{tabular}
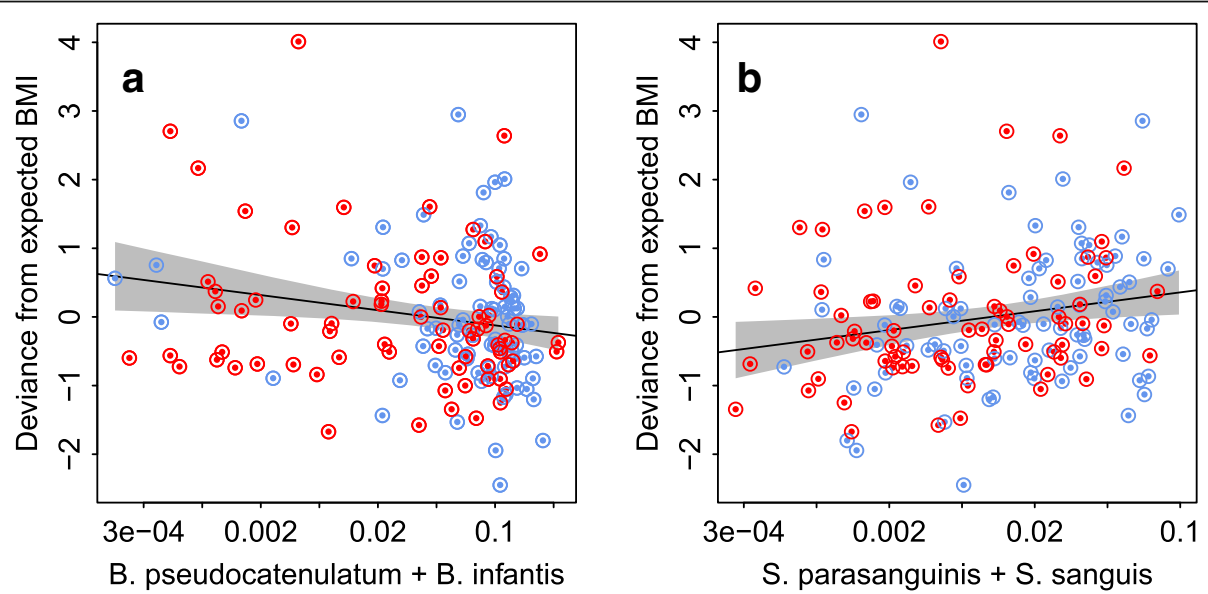

Fig. 2 Association between selected bifidobacteria (a) and streptococci (b) at 3 months of age and deviance from expected BMI at 5-6 years in Finnish (red) and Dutch (blue) children. The deviance from expected is calculated based on birth weight and breastfeeding duration. See Table 2 for details. The trend lines (shading) show linear regression (95\% confidence interval) 


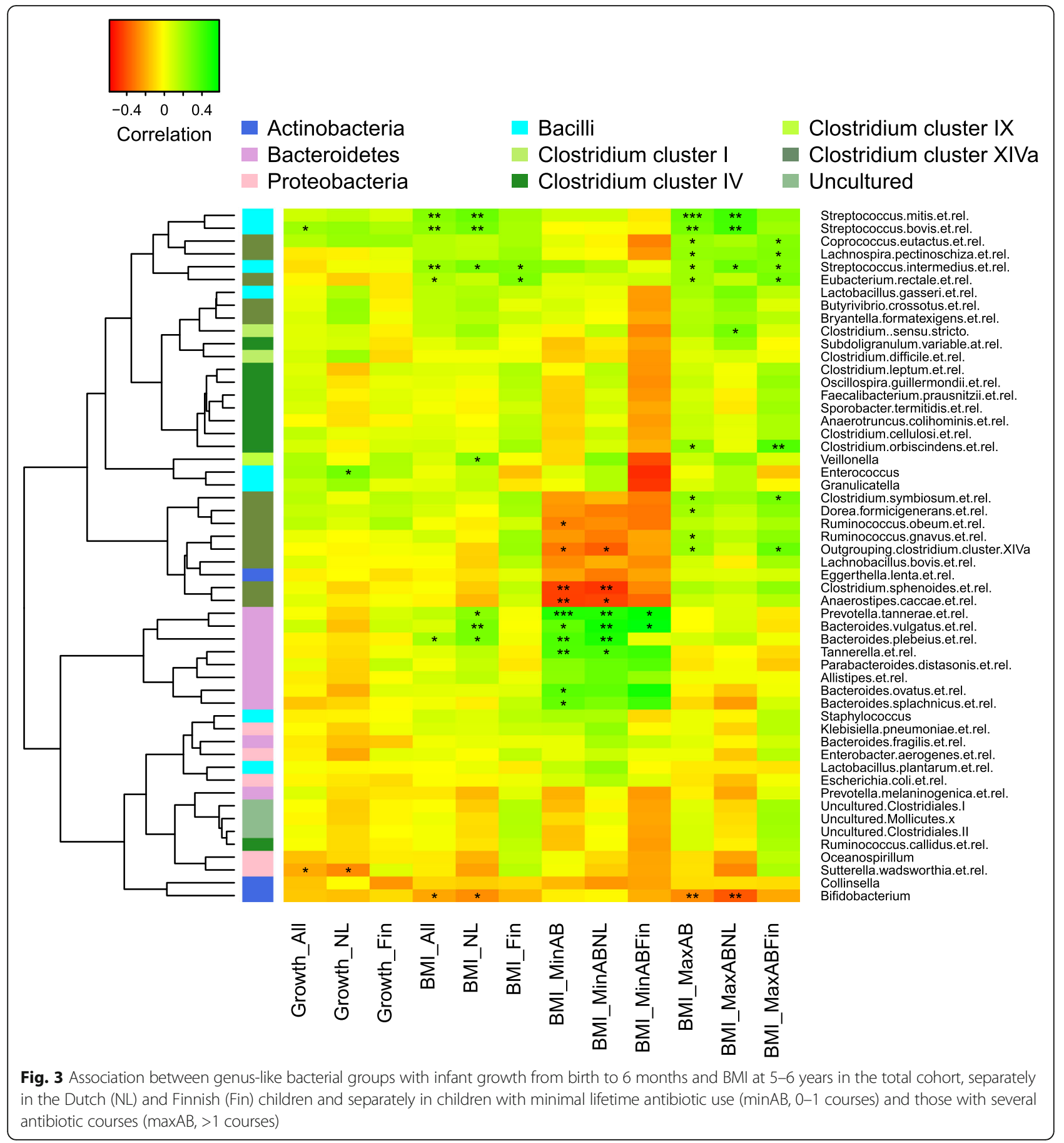

consistently associated with later BMI in both the Dutch and the Finnish cohort.

Children with a low relative abundance of Actinobacteria and a high relative abundance of Firmicutes at the age of 3 months were likely to attain a high BMI at the age of 5-6 years, but only if they received several courses of antibiotics. This is in line with our earlier finding that macrolide use in early life, which we have shown to nearly eliminate Actinobacteria in children, is required for the later antibiotic-associated increase in BMI to occur [28]. These results suggest that the earlylife microbiota composition may modify the later metabolic response to antibiotics. Antibiotic use is associated with an increase in LPS-producing Gram-negative bacteria [28], and frequent antibiotic use may thus involve recurrent LPS surges, similar to a high-fat diet [39]. It is possible that the host's metabolic responses to this depend on early-life microbial exposure. 
Two Finnish studies based on another birth cohort have noted a negative association between the relative abundance of Bifidobacterium in infancy and later BMI $[8,9]$. Moreover, high relative abundance of Firmicutes and low relative abundance of bifidobacteria has been associated with rapid growth, an obesity predictor [40], and with increased adiposity in infancy [11, 41]. Here, we found the same associations particularly among the children with a history of antibiotic use. Streptococci, which were positively associated with early growth and later BMI, form a significant component of the neonate gut microbiota [31] and inhabit the small intestine in adults [42]. Their relative abundance in faecal microbiota normally declines rapidly during the first weeks, as they are replaced by anaerobic bifidobacteria [31]. High relative abundance of streptococci and low relative abundance of bifidobacteria at 3 months likely reflects an altered maturation of the microbiota. It is possible that the microbiota composition in infancy is a reflection of, rather than a causal contributor to, the physiological, metabolic, or immunological development of the host. There are, however, indications that the microbiota actively participate in early-life metabolic programming [4-6].

Increasing amount of evidence is indicating that bifidobacteria have an important role in the host's energy metabolism. Rodent studies have shown that the negative metabolic effects of a high-fat diet are dependent on a reduction in the abundance of bifidobacteria [43-45]. Indeed, a bifidogenic synbiotic has been shown to reduce weight in overweight children [46]. Obesity and high-fat diets induce endotoxemia, an increase in the level of circulating lipopolysaccharide (LPS), which appears to be a requirement for the associated metabolic consequences $[39,43,46]$. Bifidobacteria may reduce systemic inflammation by reducing the abundance of inflammatory LPS-producing bacteria [45], by up-regulating tightjunction proteins in the gut and thus reducing the leakage of LPS and other bacterial antigens into the circulation $[43,47]$, and by stimulating regulatory $\mathrm{T}$ cells and the production of anti-inflammatory cytokines [45]. In obese adults, Bifidobacterium spp. correlate negatively with serum LPS, cholesterol, and fat mass [48].

$B$. pseudocatenulatum and B. longum have previously been shown to reduce weight gain and the metabolic effects of a high-fat diet in rodents, causing lower cholesterol and leptin levels and improved insulin sensitivity $[45,49-51]$. The mechanism is at least partly related to the amelioration of the diet-induced endotoxemia and inflammation in the gut, liver, and in adipose tissue [45, 50,51 ], and the deconjugation of bile acids [52], which influences the host's lipid metabolism and energy expenditure [23]. B. pseudocatenulatum has been shown to cause changes in the expression of hepatic genes involved in lipid metabolism [53].
In previous Dutch studies, Bacteroides species, and particularly $B$. fragilis have been associated with higher BMI outcomes in later childhood [10, 12]. We found the same association, but only in the children with minimal antibiotic exposure. Dutch children generally use antibiotics less frequently than Finnish children, which may explain why this association has previously not been observed in Finnish children. Bacteroides spp. were generally more abundant in the Finnish infants.

\section{Conclusions}

While our results do not establish causation between early-life microbiota composition and later BMI, they show that the microbiota may represent a biomarker for assessing individual risks of excessive weight gain. The results support the emerging paradigm of microbiotadependent metabolic programming in humans.

\section{Additional files}

Additional file 1: Relative abundances of bacterial groups in each sample. (XLSX $316 \mathrm{~kb}$ )

Additional file 2: $R$ script for the main analysis. ( $\mathrm{R} 4 \mathrm{~kb}$ )

Additional file 3: Bacterial taxa with significantly different relative abundances in the Dutch and Finnish cohorts. All FDR-corrected $p$ values are $<0.05$. (DOCX $145 \mathrm{~kb}$ )

Additional file 4: BMl distribution in the Finnish and Dutch cohorts. (PDF $117 \mathrm{~kb}$ )

\section{Acknowledgements}

The authors wish to thank all participating families. The sample processing for HITChip analysis, conducted by Jorn Hartman and Ineke Heikamp-de Jong, Wageningen University, is gratefully acknowledged.

\section{Funding}

The Bibo project was funded by the Netherlands Organization for Scientific Research (NWO; personal VIDI grant to CDW, number 452-04-320) and the Graduate School Behavioural Science Institute (grant number: 022.002.011). The HITChip analysis was funded by the unrestricted NWO Spinoza Award and SIAM Gravity Grant 024.002.002 to WMDV.

\section{Availability of data and materials}

The datasets and R script supporting the conclusions of this article are included within the article and its additional files.

\section{Authors' contributions}

$\mathrm{MZ}, \mathrm{MK}, \mathrm{KKu}, \mathrm{ES}$, and CdW provided the data. KKo designed the study, analysed the data, and wrote the manuscript. AS and WMdV supervised the work and critically revised the manuscript. All authors read and approved the final manuscript.

\section{Competing interests}

The authors declare that they have no competing interests.

Consent for publication

Not applicable.

Ethics approval and consent to participate

Written informed consent was obtained from all parents. The Bibo study was approved by the ethical committee of the faculty of social sciences,

Radboud University Nijmegen. The Flora study was approved by the ethical committee of Helsinki and Uusimaa Hospital district, Finland. 


\section{Author details}

Immunobiology Research Program, Department of Bacteriology and Immunology, University of Helsinki, Haartmaninkatu 3, PO box 2100014 Helsinki, Finland. ${ }^{2}$ Department of Developmental Psychology, Behavioural Science Institute, Radboud University Nijmegen, Nijmegen, The Netherlands. ${ }^{3}$ Children's Hospital, University of Helsinki and Helsinki University Central Hospital, Helsinki, Finland. ${ }^{4}$ Skin and Allergy Hospital, Department of Paediatrics, Helsinki University Central Hospital, Helsinki, Finland. ${ }^{5}$ Laboratory of Microbiology, Wageningen University, Wageningen, The Netherlands.

\section{Received: 22 September 2016 Accepted: 15 February 2017} Published online: 03 March 2017

\section{References}

1. Wang Y, Lobstein T. Worldwide trends in childhood overweight and obesity. Int J Pediatr Obes. 2006;1(1):11-25.

2. Singh AS, Mulder C, Twisk JW, Van Mechelen W, Chinapaw MJ. Tracking of childhood overweight into adulthood: a systematic review of the literature. Obes Rev. 2008;9(5):474-88.

3. Cottrell E, Ozanne S. Early life programming of obesity and metabolic disease. Physiol Behav. 2008;94(1):17-28

4. Backhed F, Ding H, Wang T, Hooper LV, Koh GY, Nagy A, Semenkovich CF, Gordon JI. The gut microbiota as an environmental factor that regulates fat storage. Proc Natl Acad Sci U S A. 2004;101(44):15718-23.

5. Ridaura VK, Faith JJ, Rey FE, Cheng J, Duncan AE, Kau AL, Griffin NW, Lombard V, Henrissat B, Bain JR, Muehlbauer MJ, Ilkayeva O, Semenkovich CF, Funai K, Hayashi DK, Lyle BJ, Martini MC, Ursell LK, Clemente JC, Van Treuren W, Walters WA, Knight R, Newgard CB, Heath AC, Gordon Jl. Gut microbiota from twins discordant for obesity modulate metabolism in mice. Science. 2013;341(6150):1241214.

6. Cox LM, Yamanishi S, Sohn J, Alekseyenko AV, Leung JM, Cho I, Kim SG, Li $\mathrm{H}$, Gao Z, Mahana D. Altering the intestinal microbiota during a critical developmental window has lasting metabolic consequences. Cell. 2014; 158(4):705-21.

7. Cox LM, Blaser MJ. Pathways in microbe-induced obesity. Cell Metab. 2013; 17(6):883-94.

8. Kalliomaki M, Collado MC, Salminen S, Isolauri E. Early differences in fecal microbiota composition in children may predict overweight. Am J Clin Nutr. 2008:87(3):534-8

9. Luoto R, Kalliomaki M, Laitinen K, Delzenne NM, Cani PD, Salminen S, Isolauri E. Initial dietary and microbiological environments deviate in normal-weight compared to overweight children at 10 years of age. $J$ Pediatr Gastroenterol Nutr. 2011;52(1):90-5.

10. Vael C, Verhulst SL, Nelen V, Goossens H, Desager KN. Intestinal microflora and body mass index during the first three years of life: an observational study. Gut Pathogens. 2011:3:8

11. Dogra S, Sakwinska O, Soh S, Ngom-Bru C, Brück WM, Berger B, Brüssow H, Lee YS, Yap F, Chong Y. Dynamics of infant gut microbiota are influenced by delivery mode and gestational duration and are associated with subsequent adiposity. MBio. 2015:6(1):e02419-14.

12. Scheepers L, Penders J, Mbakwa C, Thijs C, Mommers M, Arts I. The intestinal microbiota composition and weight development in children: the KOALA Birth Cohort Study. Int J Obes. 2015;39(1):16-25.

13. Ajslev TA, Andersen CS, Gamborg M, Sorensen TIA, Jess T. Childhood overweight after establishment of the gut microbiota: the role of delivery mode, pre-pregnancy weight and early administration of antibiotics. Int J Obes. 2011:35(4):522-9.

14. Trasande L, Blustein J, Liu M, Corwin E, Cox LM, Blaser MJ. Infant antibiotic exposures and early-life body mass. Int J Obes. 2013:37(1):16-23.

15. Azad MB, Bridgman SL, Becker AB, Kozyrskyj AL. Infant antibiotic exposure and the development of childhood overweight and central adiposity. Int J Obes. 2014:38(10):1290-8

16. Bailey LC, Forrest CB, Zhang P, Richards TM, Livshits A, DeRusso PA. Association of antibiotics in infancy with early childhood obesity. JAMA Pediatr. 2014;168(11):1063-9.

17. Saari A, Virta LJ, Sankilampi U, Dunkel L, Saxen H. Antibiotic exposure in infancy and risk of being overweight in the first 24 months of life. Pediatrics. 2015:135(4):617-26.

18. Cho I, Yamanishi S, Cox L, Methé BA, Zavadil J, Li K, Gao Z, Mahana D, Raju $\mathrm{K}$, Teitler I. Antibiotics in early life alter the murine colonic microbiome and adiposity. Nature. 2012;488(7413):621-6.
19. Nobel Y, Cox L, Blaser M, et al. Metabolic and metagenomic outcomes from early-life pulsed antibiotic treatment. Nat Commun. 2015;7483. doi:10.1038/ ncomms8486.

20. Thompson AL. Developmental origins of obesity: early feeding environments, infant growth, and the intestinal microbiome. Am J Hum Biol. 2012;24(3):350-60.

21. Li H, Zhou Y, Liu J. The impact of cesarean section on offspring overweight and obesity: a systematic review and meta-analysis. Int J Obes. 2013;37(7):893-9.

22. Watanabe M, Houten SM, Mataki C, Christoffolete MA, Kim BW, Sato H, Messaddeq N, Harney JW, Ezaki O, Kodama T. Bile acids induce energy expenditure by promoting intracellular thyroid hormone activation. Nature. 2006;439(7075):484-9.

23. Joyce SA, MacSharry J, Casey PG, Kinsella M, Murphy EF, Shanahan F, Hill C, Gahan CG. Regulation of host weight gain and lipid metabolism by bacterial bile acid modification in the gut. Proc Natl Acad Sci U S A. 2014; 111(20):7421-6.

24. Song MJ, Kim KH, Yoon JM, Kim JB. Activation of Toll-like receptor 4 is associated with insulin resistance in adipocytes. Biochem Biophys Res Commun. 2006;346(3):739-45.

25. Cani PD, Amar J, Iglesias MA, Poggi M, Knauf C, Bastelica D, Neyrinck AM, Fava F, Tuohy KM, Chabo C, Waget A, Delmee E, Cousin B, Sulpice T, Chamontin B, Ferrieres J, Tanti JF, Gibson GR, Casteilla L, Delzenne NM, Alessi MC, Burcelin R. Metabolic endotoxemia initiates obesity and insulin resistance. Diabetes. 2007:56(7):1761-72

26. Camp JG, Jazwa AL, Trent CM, Rawls JF. Intronic cis-regulatory modules mediate tissue-specific and microbial control of angpt|4/fiaf transcription. PLoS Genet. 2012;8(3):e1002585.

27. Lin HV, Frassetto A, Kowalik Jr EJ, Nawrocki AR, Lu MM, Kosinski JR, Hubert JA, Szeto D, Yao X, Forrest G, Marsh DJ. Butyrate and propionate protect against diet-induced obesity and regulate gut hormones via free fatty acid receptor 3-independent mechanisms. PLoS One. 2012;7(4):e35240.

28. Korpela K, Salonen A, Virta L, Kekkonen R, Forslund K, Bork P, de Vos W. Intestinal microbiome is associated with lifetime antibiotic use in Finnish pre-school children. Nat Commun. 2016;7:10410

29. Korpela K, Salonen A, Virta $\amalg$, Kekkonen RA, de Vos WM. Association of early-life antibiotic use and protective effects of breastfeeding: role of the intestinal microbiota. JAMA Pediatr. 2016;170(8):750-757. doi:10.1001/ jamapediatrics.2016.0585.

30. Kuitunen M, Kukkonen K, Juntunen-Backman K, Korpela R, Poussa T, Tuure T, Haahtela T, Savilahti E. Probiotics prevent lgE-associated allergy until age 5 years in cesarean-delivered children but not in the total cohort. J Allergy Clin Immunol. 2009;123(2):335-41.

31. Zijlmans MA, Korpela K, Riksen-Walraven JM, de Vos WM, de Weerth C. Maternal prenatal stress is associated with the infant intestinal microbiota. Psychoneuroendocrinology. 2015;53:233-45.

32. Adriaenssens N, Coenen S, Versporten A, Muller A, Minalu G, Faes C, Vankerckhoven V, Aerts M, Hens N, Molenberghs G. European Surveillance of Antimicrobial Consumption (ESAC): outpatient antibiotic use in Europe (1997-2009). J Antimicrob Chemother. 2011;66 suppl 6:vi3-vi12.

33. Korpela K, Salonen A, Virta $\amalg$, Kumpu M, Kekkonen RA, de Vos WM. Lactobacillus rhamnosus GG intake modifies preschool children's intestinal microbiota, alleviates penicillin-associated changes, and reduces antibiotic use. PLoS One. 2016;11(4):e0154012.

34. Salonen A, Nikkila J, Jalanka-Tuovinen J, Immonen O, Rajilic-Stojanovic M, Kekkonen RA, Palva A, de Vos WM. Comparative analysis of fecal DNA extraction methods with phylogenetic microarray: effective recovery of bacterial and archaeal DNA using mechanical cell lysis. J Microbiol Methods. 2010;81(2):127-34

35. Rajilic-Stojanovic M, Heilig HGHJ, Molenaar D, Kajander K, Surakka A, Smidt $\mathrm{H}$, de Vos WM. Development and application of the human intestinal tract chip, a phylogenetic microarray: analysis of universally conserved phylotypes in the abundant microbiota of young and elderly adults. Environ Microbiol. 2009;11(7):1736-51.

36. Lahti L, Torrente A, Elo LL, Brazma A, Rung J. A fully scalable online preprocessing algorithm for short oligonucleotide microarray atlases. Nucleic Acids Res. 2013:41(10):e110.

37. R Core Team: R. A language and environment for statistical computing. 2012

38. Oksanen J, Blanchet FG, Kindt R, Legendre P, Minchin PR, O'Hara RB, Simpson GL, Solymos P, Stevens MHH, Wagner H. vegan: Community Ecology Package. 2013. R package version 2.0-6.

39. Pendyala S, Walker JM, Holt PR. A high-fat diet is associated with endotoxemia that originates from the gut. Gastroenterology. 2012;142(5): 1100-1. e2. 
40. Baird J, Fisher D, Lucas P, Kleijnen J, Roberts H, Law C. Being big or growing fast: systematic review of size and growth in infancy and later obesity. BMJ. 2005;331 (7522):929.

41. Bergstrom A, Skov TH, Bahl Ml, Roager HM, Christensen LB, Ejlerskov KT, Molgaard C, Michaelsen KF, Licht TR. Establishment of intestinal microbiota during early life: a longitudinal, explorative study of a large cohort of Danish infants. Appl Environ Microbiol. 2014;80(9):2889-900.

42. Booijink CC, El-Aidy S, Rajilić-Stojanović M, Heilig HG, Troost FJ, Smidt H, Kleerebezem M, De Vos WM, Zoetendal EG. High temporal and interindividual variation detected in the human ileal microbiota. Environ Microbiol. 2010;12(12):3213-27.

43. Cani PD, Neyrinck AM, Fava F, Knauf C, Burcelin RG, Tuohy KM, Gibson G, Delzenne NM. Selective increases of bifidobacteria in gut microflora improve high-fat-diet-induced diabetes in mice through a mechanism associated with endotoxaemia. Diabetologia. 2007:50(11):2374-83.

44. Cani PD, Delzenne NM. The role of the gut microbiota in energy metabolism and metabolic disease. Curr Pharm Des. 2009:15(13):1546-58.

45. Moya-Pérez A, Neef A, Sanz Y. Bifidobacterium pseudocatenulatum CECT 7765 reduces obesity-associated inflammation by restoring the lymphocytemacrophage balance and gut microbiota structure in high-fat diet-fed mice. PLoS One. 2015;10(7):e0126976.

46. Safavi M, Farajian S, Kelishadi R, Mirlohi M, Hashemipour M. The effects of synbiotic supplementation on some cardio-metabolic risk factors in overweight and obese children: a randomized triple-masked controlled trial. Int J Food Sci Nutr. 2013;64(6):687-93.

47. Moratalla A, Gómez-Hurtado I, Santacruz A, Moya Á, Peiró G, Zapater P, González-Navajas JM, Giménez P, Such J, Sanz Y. Protective effect of Bifidobacterium pseudocatenulatum CECT7765 against induced bacterial antigen translocation in experimental cirrhosis. Liver Int. 2014;34(6):850-8.

48. Salazar N, Dewulf EM, Neyrinck AM, Bindels LB, Cani PD, Mahillon J, de Vos WM, Thissen J, Gueimonde M, Clara G. Inulin-type fructans modulate intestinal Bifidobacterium species populations and decrease fecal shortchain fatty acids in obese women. Clin Nutr. 2015;34(3):501-7.

49. Chen JJ, Wang R, Li XF, Wang RL. Bifidobacterium longum supplementation improved high-fat-fed-induced metabolic syndrome and promoted intestinal Reg I gene expression. Exp Biol Med. 2011;236(7):823-31.

50. An HM, Park SY, Lee DK, Kim JR, Cha MK, Lee SW, Lim HT, Kim KJ, Ha NJ. Antiobesity and lipid-lowering effects of Bifidobacterium spp. in high fat diet-induced obese rats. Lipids Health Dis. 2011:10(1):116.

51. Cano PG, Santacruz A, Trejo FM, Sanz Y. Bifidobacterium CECT 7765 improves metabolic and immunological alterations associated with obesity in high-fat diet-fed mice. Obesity. 2013;21(11):2310-21.

52. Mariam RS, Yap KW, Lim LC, Kharidah M, Shuhaimi M, Abdullah S, Ali AM, Atiqah AN, YAZID AM. Strain differences in deconjugation of bile acids in Bifidobacterium pseudocatenulatum isolates. Bioscience Microflora. 2004; 23(2):93-8.

53. Moya-Perez A, Romo-Vaquero M, Tomas-Barberan F, Sanz Y, García-Conesa M. Hepatic molecular responses to Bifidobacterium pseudocatenulatum CECT 7765 in a mouse model of diet-induced obesity. Nutr Metab Cardiovasc Dis. 2014;24(1):57-64.

\section{Submit your next manuscript to BioMed Central and we will help you at every step:}

- We accept pre-submission inquiries

- Our selector tool helps you to find the most relevant journal

- We provide round the clock customer support

- Convenient online submission

- Thorough peer review

- Inclusion in PubMed and all major indexing services

- Maximum visibility for your research

Submit your manuscript at www.biomedcentral.com/submit

Biomed Central 